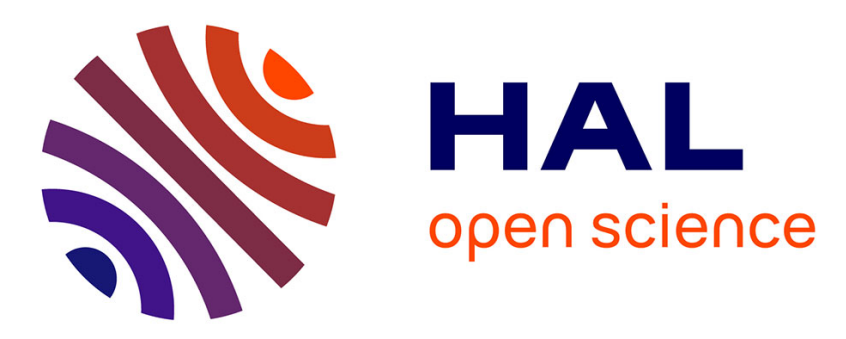

\title{
Three-dimensional passive earth pressures by kinematical approach
}

Abdul-Hamid Soubra, Pierre Regenass

\section{To cite this version:}

Abdul-Hamid Soubra, Pierre Regenass. Three-dimensional passive earth pressures by kinematical approach. Journal of Geotechnical and Geoenvironmental Engineering, 2000, 126 (11), pp.969-978. 10.1061/(ASCE)1090-0241(2000)126:11(969) . hal-01007383

\section{HAL Id: hal-01007383 \\ https://hal.science/hal-01007383}

Submitted on 16 Jun 2014

HAL is a multi-disciplinary open access archive for the deposit and dissemination of scientific research documents, whether they are published or not. The documents may come from teaching and research institutions in France or abroad, or from public or private research centers.
L'archive ouverte pluridisciplinaire HAL, est destinée au dépôt et à la diffusion de documents scientifiques de niveau recherche, publiés ou non, émanant des établissements d'enseignement et de recherche français ou étrangers, des laboratoires publics ou privés. 


\title{
Three-Dimensional Passive Earth Pressures by Kinematical ApProach
}

\author{
By Abdul-Hamid Soubra, ${ }^{1}$ Member, ASCE, and Pierre Regenass ${ }^{2}$
}

\begin{abstract}
The 3D passive earth pressure problem is investigated by the upper-bound method in limit analysis. Three kinematically admissible failure mechanisms referred to as $M 1, M n$, and $M n t$ are considered for the calculation schemes. The $M 1$ mechanism is an extension into three dimensions of the classical 2D Coulomb mechanism. The $M n$ mechanism is a generalization of the $M 1$ mechanism and is composed of a sequence of rigid blocks. Finally, the $M n t$ mechanism is a more elaborate mechanism in which the final block of the $M n$ mechanism is truncated by two portions of right circular cones. The lowest upper-bound solutions given by the present analysis are compared with other authors' results and presented in a form of design tables relating the geometrical parameters, soil properties, and the 3D passive earth pressure coefficients.
\end{abstract}

\section{INTRODUCTION}

The problem of the passive earth pressures acting on rigid retaining walls has been widely studied in the literature. Most of the research effort has concentrated on a refinement of 2D analyses with little attention given to $3 \mathrm{D}$ aspects. The calculation schemes are based on either the limit-equilibrium method (Coulomb 1773; Terzaghi 1943; Shields and Tolunay 1972, 1973; Rahardjo and Fredlund 1984; Zakerzadeh et al. 1999), the slip line method (Caquot and Kérisel 1949; Sokolovski 1960), or the limit analysis methods (Lysmer 1970; Lee and Herington 1972; Chen and Rosenfarb 1973; Soubra et al. 1999; Soubra 2000).

In this paper, the $3 \mathrm{D}$ nature of the passive earth pressure problem is investigated by the upper-bound method of the limit analysis theory. Three kinematically admissible failure mechanisms are considered for the calculation schemes. The analysis will consider the general case of a frictional and cohesive ( $\phi$ and $c$ ) soil with an eventual surcharge loading $q$ on the ground surface. The numerical results of the 3D passive earth pressures are presented in the form of dimensionless coefficients $K_{p \gamma}, K_{p c}$, and $K_{p q}$ representing the effect of soil weight, cohesion, and surcharge loading, respectively.

\section{THEORETICAL ANALYSIS}

It is well known that the $3 \mathrm{D}$ nature of the passive earth pressure problem has the favorable effect of increasing the passive earth pressures exerted on the wall. In this paper, the increase of the passive pressures due to the decrease of the wall breadth is investigated using the kinematical approach of the limit analysis theory. The following assumptions have been made in the analysis:

- The wall of dimensions $b \times h$ ( $b=$ breadth; $h=$ height $)$ is vertical, and the backfill is horizontal.

- A translational soil-wall movement is assumed.

- The soil is homogeneous and isotropic. It is assumed to be an associated flow rule Coulomb material obeying Hill's maximal work principle.

${ }^{1}$ Prof., IUP Génie Civil et Infrastructures, LGCNSN, Bd. de l'université, BP 152, 44603 Saint-Nazaire cedex, France; formerly, ENSAIS, 24, Bld de la Victoire, 67084 Strasbourg cedex, France. E-mail: Ahamid.Soubra@ensais.u-strasbg.fr

${ }^{2}$ Asst., ENSAIS, 24, Bld de la Victoire, 67084 Strasbourg cedex, France. E-mail: Pierre.Regenass@ensais.u-strasbg.fr
- The angle of friction $\delta$ at the soil-structure interface is assumed to be constant. This hypothesis is in conformity with the translational kinematics assumed in this paper.

- A tangential adhesive force $P_{a}$ is assumed to act at the soil-structure interface. The intensity of this force is $c(\tan$ $\delta / \tan \phi) b h$.

- The velocity at the soil-structure interface is assumed tangential to the wall (Chen 1975). Other investigators (Collins 1969, 1973; Mroz and Drescher 1969) assumed that the interfacial velocity is inclined at $\delta$ to the wall in order to respect the normality condition. Both hypotheses lead to the same result of the limit load (Drescher and Detournay 1993; Michalowski 1999). [For more details, the reader may refer to Soubra (2000).]

\section{Upper- and Lower-Bound Theorems of Limit Analysis}

As is well known, the limit theorems of the limit analysis theory enable us to determine upper- and lower-bound solutions for the stability problems of a rigid perfectly plastic material. Whereas the lower-bound method is complex due to the fact that it requires the construction of a complete stress field, the upper-bound method is simpler: Equating the rate of external work to the internal rate of energy dissipation for a kinematically admissible velocity field gives an unsafe solution of the collapse or limit load. A kinematically admissible velocity field is one that satisfies the flow rule, the velocity boundary conditions, and compatibility. Note that the velocity field at collapse is often modeled by a mechanism consisting of rigid blocks that move with constant velocities. Because no general plastic deformation of the soil mass is permitted to occur, the energy is dissipated solely at the interfaces between adjacent blocks that constitute velocity discontinuities. This kind of velocity field will be used herein.

It should be noted that the limit load calculated from limit analysis is based on the normality condition, which is not true for granular material. However, recent theoretical considerations made on translational failure mechanisms (Drescher and Detournay 1993; Michalowski and Shi 1995, 1996) allow one to conclude that, for a nonassociative material, the limit load can be obtained by the use of the flow rule associated with a new yield condition in which $c$ and $\phi$ are replaced by $c^{*}$ and $\phi^{*}$ as follows:

$$
\begin{gathered}
\tan \phi^{*}=\frac{\cos \psi \sin \phi}{1-\sin \psi \sin \phi} \\
c^{*}=\frac{\cos \psi \cos \phi}{1-\sin \psi \sin \phi}
\end{gathered}
$$

where $\psi=$ dilatancy angle. Hence, the results presented in the present paper can be used for nonassociative material provided 
that the internal friction angle $\phi$ and the cohesion $c$ are replaced with $\phi^{*}$ and $c^{*}$ calculated from (1) and (2), respectively.

\section{Failure Mechanisms}

In this paper, three translational failure mechanisms referred to as $M 1, M n$, and $M n t$ are considered for the calculation schemes. These mechanisms are presented in the following sections.

\section{One-Block Mechanism M1}

A simple failure mechanism for a rectangular vertical wall is shown diagrammatically in Fig. 1(a). This mechanism is an extension into three dimensions of the 2D well-known Coulomb mechanism. The horizontal movement of the wall $A A^{\prime} B B^{\prime}$ is accommodated by movement of the material $A A^{\prime} B B^{\prime} D D^{\prime}$. The Cartesian coordinate system is selected so that the plane of symmetry coincides with $z=0$. Fig. 1(b) shows the vertical section through $x O y$.

As shown in Fig. 1(a), the $M 1$ mechanism is composed of a single rigid block $A A^{\prime} B B^{\prime} D D^{\prime}$ bounded by the vertical plane

(a)

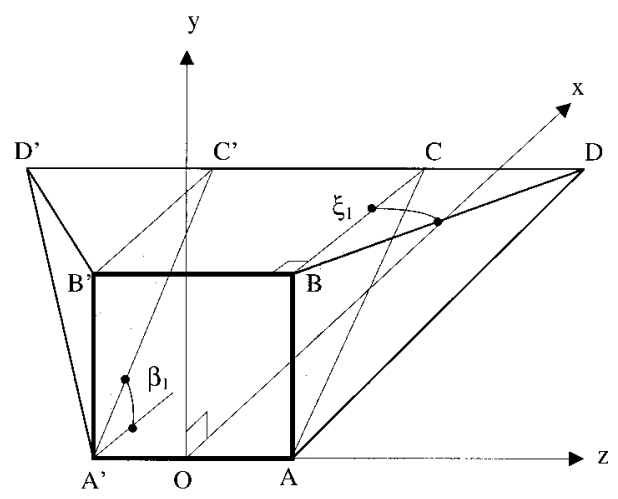

(b)

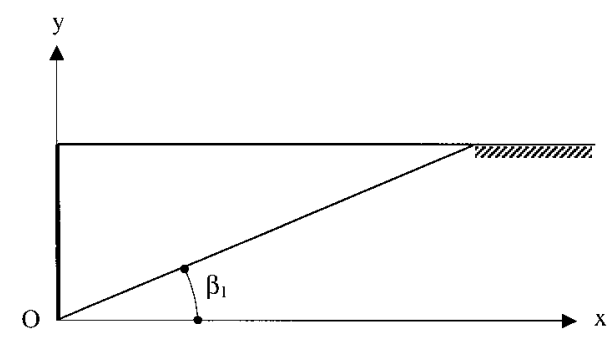

FIG. 1. (a) Failure Mechanism M1; (b) Vertical Section through $x O y$

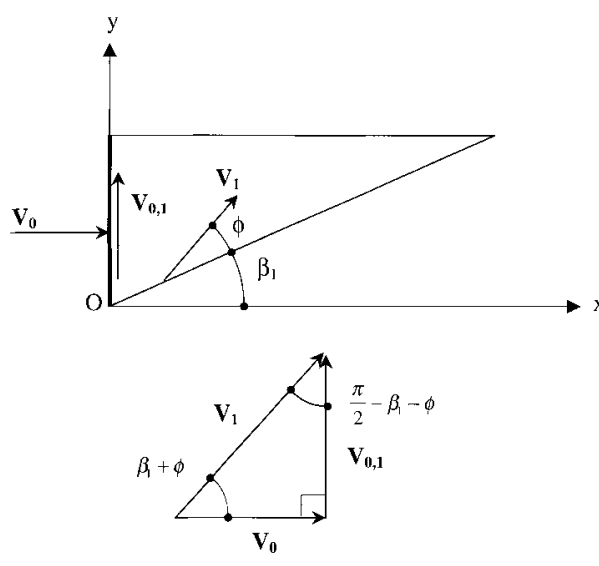

FIG. 2. Velocity Field of $M 1$ Mechanism
$A A^{\prime} B B^{\prime}$, the lower plane $A A^{\prime} D D^{\prime}$, and the lateral planes $A B D$ and $A^{\prime} B^{\prime} D^{\prime}$; it outcrops on the ground surface by the trapezoidal area $B B^{\prime} D D^{\prime}$. This mechanism is defined by a single angular parameter $\beta_{1}$, the dihedral angle between the horizontal plan and the lower plan $A A^{\prime} D D^{\prime}$.

As in the case of the $2 \mathrm{D}$ analysis, the soil mass $A A^{\prime} B B^{\prime} D D^{\prime}$ moves with velocity $\mathbf{V}_{1}$ inclined at an angle of $\beta_{1}+\phi$ to the horizontal direction (Fig. 2); the wall moves with velocity $\mathbf{V}_{0}$ and $\mathbf{V}_{0,1}$ representing the relative velocity at the soil-structure interface. All of these velocities are parallel to the vertical symmetrical plane $x O y$. Note that the velocity $\mathbf{V}_{1}$ should also make an angle $\phi$ with the lateral plane $A B D$ (respectively, $\left.A^{\prime} B^{\prime} D^{\prime}\right)$ in order to respect the normality condition. This imposes that the angle between the vector $\mathbf{V}_{1}$ and its orthogonal projection on the lateral plane $A B D$ (respectively, $A^{\prime} B^{\prime} D^{\prime}$ ) must be equal to $\phi$. This condition yields the orientation of the lateral planes $A B D$ and $A^{\prime} B^{\prime} D^{\prime}$ for a given inclination $\beta_{1}$ of the lower plane $A A^{\prime} D D^{\prime}$. It can be shown that the dihedral angle $\xi_{1}$ [cf. Fig. 1(a)] between the lateral plane $A B D$ (respectively, $\left.A^{\prime} B^{\prime} D^{\prime}\right)$ and the vertical plane $x O y$ can be expressed as

$$
\tan \xi_{1}=\frac{\sin \phi}{\sqrt{\cos ^{2} \phi-\sin ^{2}\left(\beta_{1}+\phi\right)}}
$$

where $\left.\beta_{1} \in\right] 0, \pi / 2-2 \phi\left[\right.$. The condition $\beta_{1}<\pi / 2-2 \phi$ ensures that the lateral planes are at maximum in the plane of the wall.

\section{Multiblock Mechanism Mn}

A better upper-bound solution would require a more elaborate failure mechanism $M n$ [cf. Fig. 3(a)] composed of $n$ rigid blocks. Note that in Fig. 3(a) only five blocks are shown; however, the formulation is applicable to any number of blocks. In this improved mechanism, the horizontal movement of the wall $A A^{\prime} B B^{\prime}$ is accommodated by movement of $n$ rigid blocks. Fig. 3(b) shows the vertical section through $x O y$.

As shown in Fig. 3(a), the first rigid block $A A^{\prime} B B^{\prime} D_{1} D_{1}^{\prime}$ is

(a)

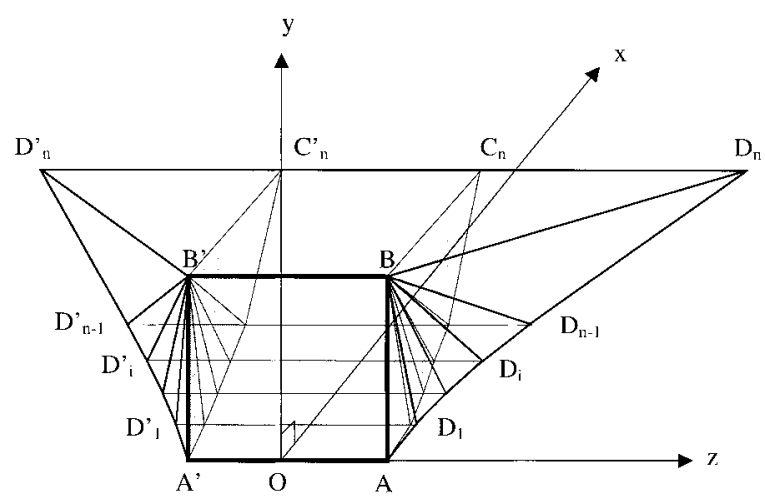

(b)

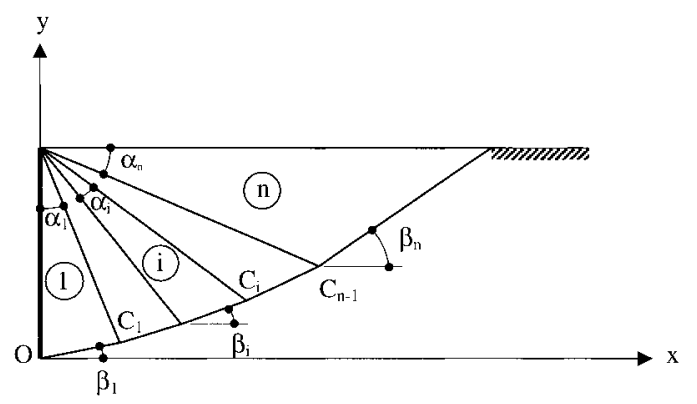

FIG. 3. (a) Failure Mechanism Mn; (b) Vertical Section through $x O y$ 
adjacent to the vertical wall and is bounded by the radial plane $B B^{\prime} D_{1} D_{1}^{\prime}$, the lower plane $A A^{\prime} D_{1} D_{1}^{\prime}$, and the lateral planes $A B D_{1}$ and $A^{\prime} B^{\prime} D_{1}^{\prime}$. An intermediate block $i$ is limited by two radial planes $B B^{\prime} D_{i-1} D_{i-1}^{\prime}$ and $B B^{\prime} D_{i} D_{i}^{\prime}$, the lower plane $D_{i-1} D_{i-1}^{\prime} D_{i} D_{i}^{\prime}$, and the lateral planes $B D_{i-1} D_{i}$ and $B^{\prime} D_{i-1}^{\prime} D_{i}^{\prime}$. The last block outcrops on the ground surface by a trapezoidal area $B B^{\prime} D_{n} D_{n}^{\prime}$. This mechanism is defined by $2 n-1$ angular parameters $\alpha_{i}(i=1, \ldots, n-1)$ and $\beta_{i}(i=1, \ldots, n)$ [cf. Fig. 3(b)].

As shown in Fig. 4, the block velocities $\mathbf{V}_{i}$ and the interblock velocities $\mathbf{V}_{i-1, i}$ are parallel to the vertical symmetrical plane $x O y$. The kinematics of the first block adjacent to the wall is similar to that of the $M 1$ mechanism. For the remaining blocks, the orientation of the lateral plane $B D_{i-1} D_{i}$ (respectively, $\left.B^{\prime} D_{i-1}^{\prime} D_{i}^{\prime}\right)$ is defined by the dihedral angle $\zeta_{i}$ between the plane $B B^{\prime} D_{i-1} D_{i-1}^{\prime}$ and the lateral plane $B D_{i-1} D_{i}$ (respectively, $\left.B^{\prime} D_{i-1}^{\prime} D_{i}^{\prime}\right)$. This angle is determined by orthogonal projection of vector $\mathbf{V}_{i}$ (cf. Fig. 4) on planes $B B^{\prime} D_{i-1} D_{i-1}^{\prime}$ and $B D_{i-1} D_{i}$ (respectively, $B^{\prime} D_{i-1}^{\prime} D_{i}^{\prime}$ ). The calculation details are given in Regenass (1999). As for the $M 1$ mechanism, $\beta_{1}<\pi /$
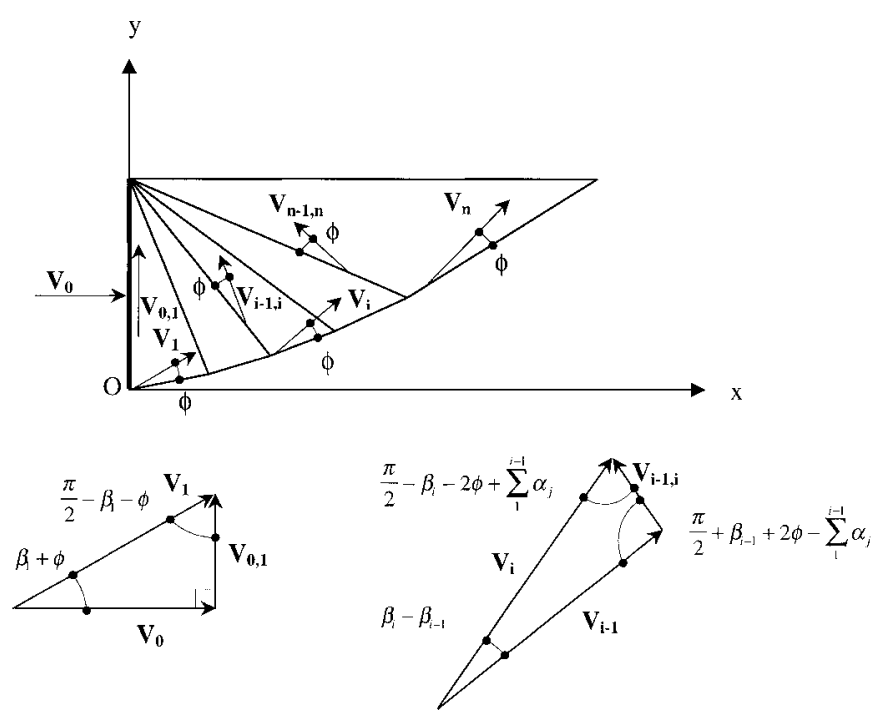

FIG. 4. Velocity Field of Mn Mechanism
$2-2 \phi$. However, the condition $\beta_{1}>0$ does not hold in the present mechanism.

\section{Truncated Multiblock Mechanism Mnt}

Further improvement in the upper-bound solution may be obtained by a volume reduction of the final block in the $M n$ mechanism. In this improved mechanism (cf. Fig. 5), the lower plane and the lateral planes of the last block of the $M n$ mechanism are truncated by two portions of right circular cones with vertices at $D_{n-1}$ and $D_{n-1}^{\prime}$, respectively. The right (respectively, left) cone is tangent to the lateral plane $B D_{n-1} D_{n}$ (respectively, $B^{\prime} D_{n-1}^{\prime} D_{n}^{\prime}$ ) and the lower plane $D_{n} D_{n}^{\prime} D_{n-1} D_{n-1}^{\prime}$. These cones have axes collinear with the velocity $V_{n}$ of the last block. They are characterized by an opening angle equal to $2 \phi$ in order to satisfy the normality condition for an associated flow rule Coulomb material. The present mechanism is kinematically admissible because it verifies all of the kinematical and velocity boundary conditions. The velocity hodographs of this mechanism are identical to the ones of the Mn mechanism.

\section{Work Equation}

The work equation is obtained by equating the rate of external work done by the external forces to the rate of internal energy dissipation along the different velocity discontinuities.

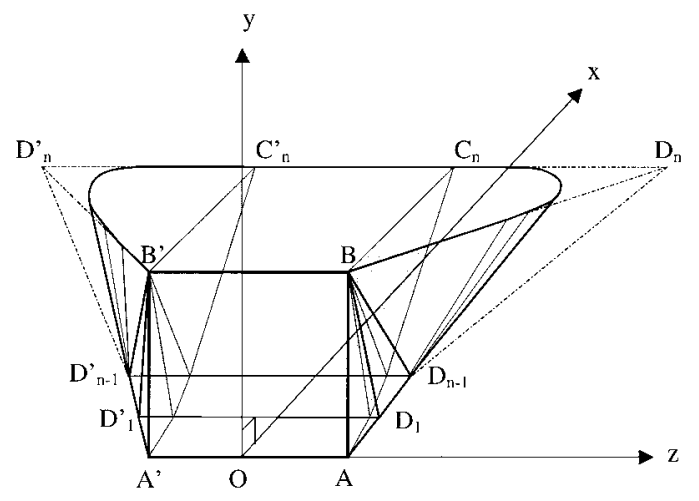

FIG. 5. Failure Mechanism Mnt

TABLE 1. Values of $K_{p \gamma}$ and Corresponding Geometrical Parameters (M1 Mechanism)

\begin{tabular}{|c|c|c|c|c|c|c|c|c|c|}
\hline \multirow{2}{*}{$\begin{array}{c}\phi \\
\text { (deg) } \\
(1)\end{array}$} & \multicolumn{3}{|c|}{$b / h=0.25$} & \multicolumn{3}{|c|}{$b / h=1$} & \multicolumn{3}{|c|}{$b / h=10$} \\
\hline & $\begin{array}{l}K_{p \gamma} \\
(2)\end{array}$ & $\begin{array}{l}\beta_{1} \\
\text { (3) }\end{array}$ & $\begin{array}{c}\mathrm{vol} / b h^{2} \\
(4)\end{array}$ & $\begin{array}{l}K_{p \gamma} \\
(5)\end{array}$ & $\begin{array}{l}\beta_{1} \\
(6)\end{array}$ & $\begin{array}{c}\mathrm{vol} / b h^{2} \\
(7)\end{array}$ & $\begin{array}{l}K_{p \gamma} \\
(8)\end{array}$ & $\begin{array}{l}\beta_{1} \\
(9)\end{array}$ & $\begin{array}{c}\mathrm{vol} / b h^{2} \\
(10)\end{array}$ \\
\hline 15 & 6.86 & 32.31 & 2.16 & 3.56 & 29.46 & 1.29 & 2.52 & 25.77 & 1.09 \\
\hline 20 & 14.82 & 26.86 & 4.00 & 6.42 & 25.21 & 1.90 & 3.83 & 22.15 & 1.33 \\
\hline 25 & 36.36 & 21.59 & 7.92 & 13.41 & 20.70 & 3.10 & 6.41 & 18.38 & 1.72 \\
\hline 30 & 110.27 & 16.33 & 18.00 & 35.36 & 15.93 & 5.98 & 12.71 & 14.40 & 2.44 \\
\hline 35 & 498.68 & 11.02 & 54.04 & 142.38 & 10.89 & 15.70 & 35.20 & 10.13 & 4.26 \\
\hline 40 & $6,103.99$ & 5.60 & 327.60 & $1,597.19$ & 5.58 & 86.16 & 244.60 & 5.40 & 13.79 \\
\hline 45 & - & - & - & - & - & - & - & - & - \\
\hline
\end{tabular}

TABLE 2. Values of $K_{p q}$ and Corresponding Geometrical Parameters (M1 Mechanism)

\begin{tabular}{|c|c|c|c|c|c|c|c|c|c|}
\hline \multirow{2}{*}{$\begin{array}{c}\phi \\
(\mathrm{deg}) \\
(1)\end{array}$} & \multicolumn{3}{|c|}{$b / h=0.25$} & \multicolumn{3}{|c|}{$b / h=1$} & \multicolumn{3}{|c|}{$b / h=10$} \\
\hline & $\begin{array}{l}K_{p q} \\
(2)\end{array}$ & $\begin{array}{c}\beta_{1} \\
(3)\end{array}$ & $\begin{array}{c}A_{G S} / b h \\
(4)\end{array}$ & $\begin{array}{l}K_{p q} \\
(5)\end{array}$ & $\begin{array}{c}\beta_{1} \\
(6)\end{array}$ & $\begin{array}{c}A_{G S} / b h \\
(7)\end{array}$ & $\begin{array}{l}K_{p q} \\
(8)\end{array}$ & $\begin{array}{l}\beta_{1} \\
(9)\end{array}$ & $\begin{array}{c}A_{G S} / b h \\
(10)\end{array}$ \\
\hline 15 & 9.03 & 32.76 & 5.60 & 4.12 & 30.36 & 2.86 & 2.58 & 26.14 & 2.19 \\
\hline 20 & 20.39 & 27.14 & 10.80 & 7.83 & 25.79 & 4.48 & 3.98 & 22.51 & 2.72 \\
\hline 25 & 51.63 & 21.72 & 22.24 & 17.25 & 21.04 & 7.79 & 6.81 & 18.72 & 3.58 \\
\hline 30 & 160.18 & 16.39 & 52.08 & 47.86 & 16.09 & 15.47 & 13.99 & 14.68 & 5.26 \\
\hline 35 & 736.18 & 11.04 & 159.28 & 201.78 & 10.95 & 44.18 & 41.21 & 10.31 & 9.76 \\
\hline 40 & $9,108.49$ & 5.60 & 977.12 & $2,348.34$ & 5.59 & 252.79 & 319.89 & 5.45 & 35.58 \\
\hline 45 & - & - & - & - & - & - & - & - & - \\
\hline
\end{tabular}


TABLE 3. Values of $K_{p c}$ and Corresponding Geometrical Parameters (M1 Mechanism)

\begin{tabular}{|c|c|c|c|c|c|c|c|c|c|}
\hline \multirow{2}{*}{$\begin{array}{c}\phi \\
(\mathrm{deg}) \\
(1)\end{array}$} & \multicolumn{3}{|c|}{$b / h=0.25$} & \multicolumn{3}{|c|}{$b / h=1$} & \multicolumn{3}{|c|}{$b / h=10$} \\
\hline & $\begin{array}{l}K_{p c} \\
(2)\end{array}$ & $\begin{array}{l}\beta_{1} \\
(3)\end{array}$ & $\begin{array}{c}A_{\text {dis }} / b h \\
(4)\end{array}$ & $\begin{array}{l}K_{p c} \\
(5) \\
\end{array}$ & $\begin{array}{l}\beta_{1} \\
(6) \\
\end{array}$ & $\begin{array}{c}A_{\text {dis }} / b h \\
(7)\end{array}$ & $\begin{array}{l}K_{p c} \\
(8)\end{array}$ & $\begin{array}{l}\beta_{1} \\
(9) \\
\end{array}$ & $\begin{array}{c}A_{\text {dis }} / \mathrm{bh} \\
(10)\end{array}$ \\
\hline 15 & 29.84 & 32.76 & 14.38 & 11.50 & 30.36 & 6.15 & 5.78 & 26.14 & 3.66 \\
\hline 20 & 53.09 & 27.14 & 22.17 & 18.59 & 25.79 & 8.35 & 8.01 & 22.51 & 4.21 \\
\hline 25 & 108.36 & 21.72 & 37.70 & 34.63 & 21.04 & 12.62 & 12.25 & 18.72 & 5.14 \\
\hline 30 & 275.44 & 16.39 & 75.03 & 80.90 & 16.09 & 22.62 & 22.24 & 14.68 & 6.97 \\
\hline 35 & $1,049.62$ & 11.04 & 199.69 & 286.43 & 10.95 & 55.14 & 57.11 & 10.31 & 11.87 \\
\hline 40 & $10,853.5$ & 5.60 & $1,086.06$ & $2,797.09$ & 5.59 & 280.84 & 379.68 & 5.45 & 39.36 \\
\hline 45 & - & - & - & - & - & - & - & - & - \\
\hline
\end{tabular}

TABLE 4. Ratios $K_{p \gamma}(3 \mathrm{D}) / K_{p \gamma}(2 \mathrm{D})$ for $\delta / \phi=1$ from $M 1$ Mechanism

\begin{tabular}{|c|c|c|c|}
\hline \multirow{2}{*}{$\begin{array}{c}\phi \\
\text { (deg) } \\
(1)\end{array}$} & \multicolumn{3}{|c|}{$K_{p \gamma}(3 \mathrm{D}) / K_{p \gamma}(2 \mathrm{D})$} \\
\hline & $\begin{array}{c}b / h=0.25 \\
\text { (2) }\end{array}$ & $\begin{array}{c}b / h=1 \\
(3)\end{array}$ & $\begin{array}{c}b / h=10 \\
\text { (4) }\end{array}$ \\
\hline $\begin{array}{l}20 \\
30 \\
40\end{array}$ & $\begin{array}{r}4.20 \\
10.92 \\
65.93\end{array}$ & $\begin{array}{r}1.82 \\
3.50 \\
17.25\end{array}$ & $\begin{array}{l}1.09 \\
1.26 \\
2.64\end{array}$ \\
\hline
\end{tabular}

TABLE 5. $\quad K_{p \gamma}$ versus Number of Rigid Blocks $n$ from $M n$ Mechanism $\left(\phi=45^{\circ} ; \delta / \phi=1 ;\right.$ and $b / h=0.25,1$, and 10$)$

\begin{tabular}{c|c|c|c|c|r|r}
\hline \hline & \multicolumn{3}{|c|}{$b / h$} & \multicolumn{3}{c}{ Reduction (\%) } \\
\cline { 2 - 7 }$n$ & 0.25 & 1 & 10 & 0.25 & 1 & 10 \\
$(1)$ & $(2)$ & $(3)$ & $(4)$ & $(5)$ & $(6)$ & $(7)$ \\
\hline 2 & $1,981.59$ & 533.19 & 98.35 & - & - & - \\
3 & $1,515.94$ & 411.15 & 79.49 & 23.50 & 22.89 & 19.17 \\
4 & $1,404.46$ & 381.83 & 74.85 & 7.35 & 7.13 & 5.85 \\
5 & $1,359.87$ & 370.08 & 72.97 & 3.18 & 3.08 & 2.51 \\
6 & $1,337.47$ & 364.18 & 72.02 & 1.65 & 1.59 & 1.30 \\
7 & $1,324.62$ & 360.80 & 71.48 & 0.96 & 0.93 & 0.76 \\
8 & $1,316.56$ & 358.67 & 71.14 & 0.61 & 0.59 & 0.48 \\
\hline \hline
\end{tabular}

The external forces contributing to the rate of external work consist of the passive earth force $P_{p}$, the weight of the soil mass in motion, and the surcharge $q$ on the ground surface. The total rate of external work is given by

$$
\dot{W}=\dot{W}_{P_{p}}+\dot{W}_{\gamma}+\dot{W}_{q}
$$

where

$$
\begin{gathered}
\dot{W}_{P_{p}}=P_{p} \cos \delta \cos \left(\beta_{1}+\phi\right) V_{1} \\
\dot{W}_{\gamma}=-\gamma \sum_{i=1}^{n} \operatorname{vol}_{i} \sin \left(\beta_{i}+\phi\right) V_{i} \\
\dot{W}_{q}-q A_{\mathrm{GS}} \sin \left(\beta_{n}+\phi\right) V_{n}
\end{gathered}
$$

where $\operatorname{vol}_{i}=$ volume of block $i$; and $A_{\mathrm{GS}}=$ area of the failure mechanism at the ground surface.

Energy is dissipated at the soil-wall interface, at the lower and lateral planes between the material at rest and the material in motion, at the radial plane(s) separating the rigid block(s), and at the conical surfaces between the lateral and the lower planes in the Mnt mechanism. The total rate of energy dissipation is given by

$$
\dot{D}=\dot{D}_{w}+\dot{D}_{\text {low }+ \text { lat }+ \text { rad }+ \text { con }}
$$

where

$$
\dot{D}_{w}=\left(P_{p} \sin \delta+P_{a}\right) V_{0,1}
$$

$$
\begin{aligned}
& \dot{D}_{\text {low }+ \text { lat }+ \text { rad }+ \text { con }} \\
& \quad=c \cos \phi\left[V_{i} \sum_{i=1}^{n}\left(A_{\text {low }_{i}}+A_{\text {lat }_{i}}\right)+V_{n} A_{\text {con }}+V_{i-1, i} \sum_{i=1}^{n-1} A_{\mathrm{rad}_{i}}\right]
\end{aligned}
$$
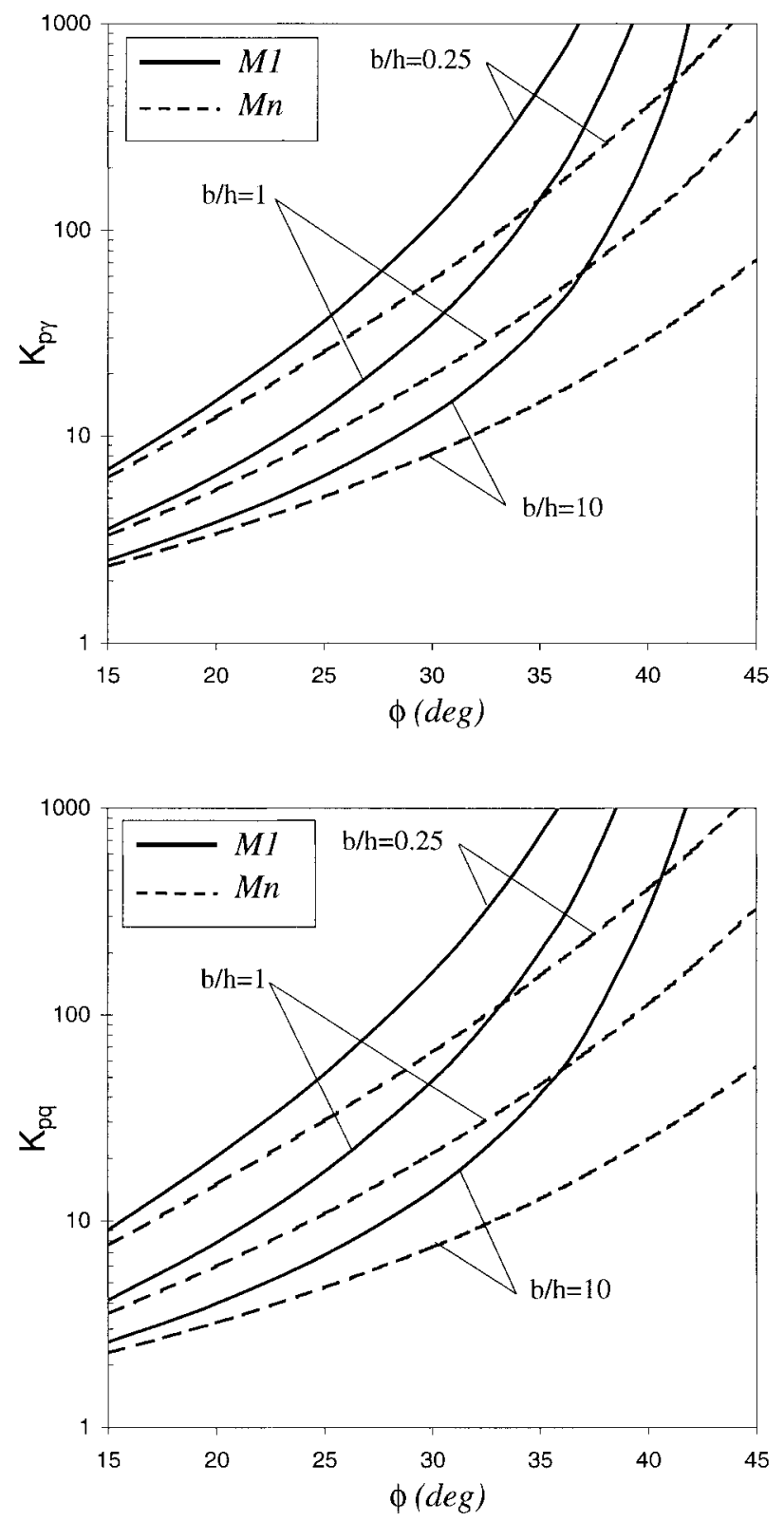

FIG. 6. Comparison of $K_{p \gamma}$ and $K_{p q}$ between $M 1$ and $M n$ Mechanisms $(\delta / \phi=1)$

By equating the total rate of external work to the total rate of energy dissipation along the different velocity discontinuities, one obtains

$$
P_{p}=K_{p \gamma} \cdot \gamma \cdot \frac{h^{2}}{2} \cdot b+K_{p c} \cdot c \cdot h \cdot b+K_{p q} \cdot q \cdot h \cdot b
$$


TABLE 6. Ratios $K_{p \gamma}(3 \mathrm{D}) / K_{p \gamma}(2 \mathrm{D})$ for $\delta / \phi=1$ from $M n$ Mechanism

\begin{tabular}{c|c|c|c}
\hline \hline \multirow{2}{*}{$\begin{array}{c}|| 3 \\
(\mathrm{deg})\end{array}$} & $b / h=0.25$ & $b / h=1$ & $b / h=10$ \\
\cline { 2 - 4 }$(1)$ & $(2)$ & $(3)$ & $(4)$ \\
\hline 20 & 3.95 & 1.75 & 1.08 \\
30 & 8.33 & 2.85 & 1.19 \\
40 & 20.12 & 5.79 & 1.48 \\
\hline \hline
\end{tabular}

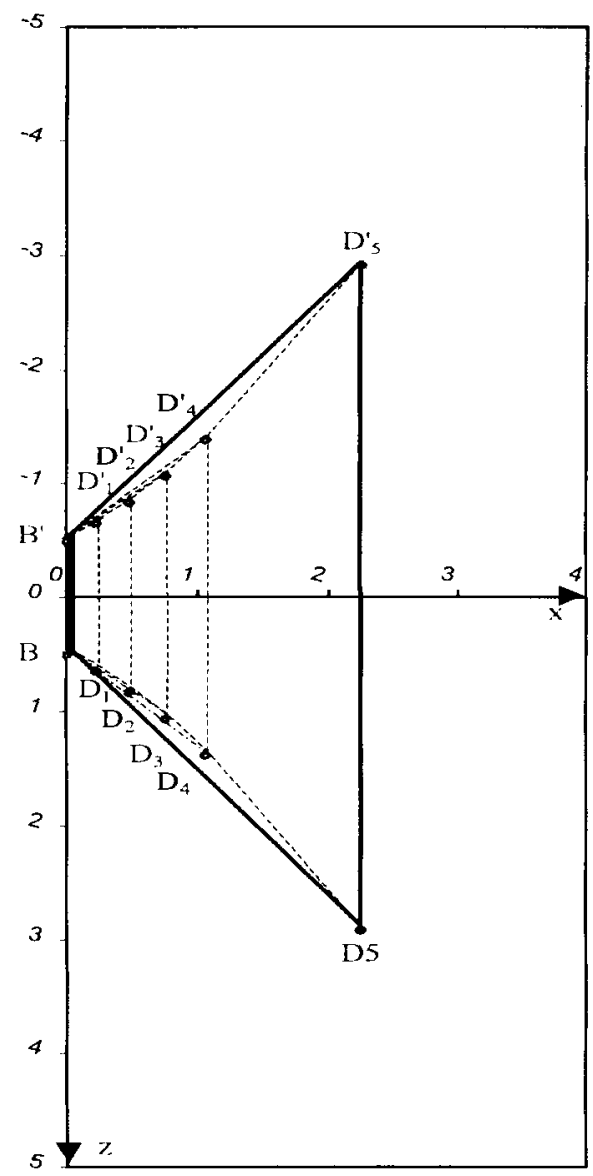

(a)

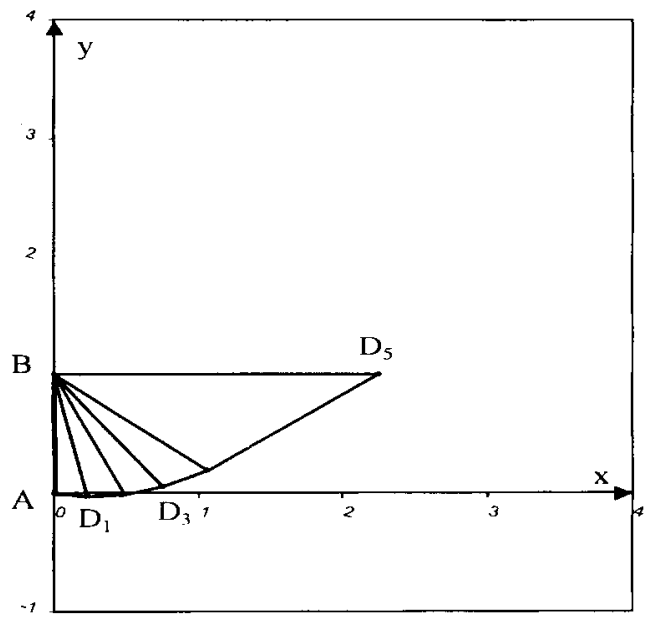

(b)

FIG. 7. Traces of Mn Mechanism: (a) Plan View; (b) Vertical Section through $x O y\left(\phi=30^{\circ}, \delta / \phi=1\right.$, and $\left.b / h=1\right)$ where $K_{p \gamma}, K_{p c}$, and $K_{p q}=$ passive earth pressure coefficients due to soil weight, cohesion, and surcharge loading, respectively. These coefficients are function of $\phi, \delta$, and $b / h$.

\section{NUMERICAL RESULTS}

The most critical passive earth pressure coefficients can be obtained by a minimization procedure of these coefficients with respect to the angular parameters describing the different failure mechanisms. Three computer programs using the VBA programming language that resides in Microsoft Excel have been written to define the coefficients of passive earth pressures as function of the mechanisms' parameters. The minimization procedure is performed using the Solver optimization tool of Microsoft Excel. The method of minimization used is the general reduced gradient method. The programs give the minimal passive earth pressure coefficients and the corresponding critical slip surfaces. In the following sections, one first presents the $K_{p \gamma}, K_{p q}$, and $K_{p c}$ coefficients obtained from the three failure mechanisms. Then, in the spirit of the upperbound approach, the lesser of the three solutions is given in the form of design tables for practical use in geotechnical engineering.

\section{Results from M1 Mechanism}

Some results from the $M 1$ mechanism are presented in Tables 1-3 where the values of $K_{p \gamma}, K_{p q}$, and $K_{p c}$ are tabulated for $\phi$ ranging from $15^{\circ}$ to $45^{\circ}$, for $\delta / \phi=1$, and for three values of $b / h(b / h=0.25,1$, and 10$)$. The optimum values of the parameter $\beta_{1}$ and the corresponding normalized critical geometry of the potentially sliding mass (i.e., vol $/ b h^{2}$ for $K_{p \gamma}$, $A_{\mathrm{GS}} / b h$ for $K_{p q}$ and $A_{\mathrm{dis}} / b h$ for $K_{p c}$ ) are also listed against the coefficients of passive earth pressures $K$ where vol $=$ total volume of the soil mass in motion; and $A_{\text {dis }}=$ area of velocity discontinuities.

Note that for $\phi=45^{\circ}$, there is no solution since the restrictive condition concerning angle $\beta_{1}$ implies that $\beta_{1}=0$ in that particular case. Tables $1-3$ clearly shows that the passive earth pressure coefficients and the corresponding optimal geometry (i.e., volume or surface) increase with increasing $\phi$. This increase is significant for great $\phi$ values. For instance, for $b / h$ $=1$ and $\delta / \phi=1$, an increase in the soil internal friction angle from $20^{\circ}$ to $25^{\circ}$ increases the coefficient $K_{p \gamma}$ by a factor of 2.1 and the volume vol $/ b h^{2}$ by 1.6 . However, an increase in $\phi$ from $35^{\circ}$ to $40^{\circ}$ increases $K_{p \gamma}$ by a factor of 11.2 and the volume $\mathrm{vol} / b h^{2}$ by 5.5 . Hence, the present mechanism seems to greatly overestimate the passive earth pressure coefficients for great $\phi$ values.

Of particular interest in Tables 2 and 3 is the same optimal parameter $\beta_{1}$ obtained from the minimization of both $K_{p q}$ and $K_{p c}$ coefficients. It is also interesting to note that these coefficients are related by the following relationship [cf. theorem of corresponding states of Caquot (Caquot and Kérisel 1949)]:

TABLE 7. $K_{p \gamma}$ versus Number of Rigid Blocks $\boldsymbol{n}$ from Mnt Mechanism $\left(\phi=45^{\circ} ; \delta / \phi=1 ;\right.$ and $b / h=0.25,1$, and 10)

\begin{tabular}{|c|c|c|c|c|c|c|}
\hline \multirow[b]{2}{*}{$\begin{array}{c}n \\
(1)\end{array}$} & \multicolumn{3}{|c|}{$b / h$} & \multicolumn{3}{|c|}{ Reduction (\%) } \\
\hline & $\begin{array}{c}0.25 \\
(2)\end{array}$ & $\begin{array}{c}1 \\
\text { (3) }\end{array}$ & $\begin{array}{l}10 \\
(4)\end{array}$ & $\begin{array}{c}0.25 \\
(5)\end{array}$ & $\begin{array}{c}1 \\
(6)\end{array}$ & $\begin{array}{l}10 \\
(7)\end{array}$ \\
\hline 2 & 784.56 & 235.81 & 69.14 & - & - & - \\
\hline 3 & 728.41 & 217.45 & 61.53 & 7.16 & 7.79 & 11.01 \\
\hline 4 & 717.13 & 213.71 & 59.84 & 1.55 & 1.72 & 2.74 \\
\hline 5 & 713.09 & 212.36 & 59.22 & 0.56 & 0.63 & 1.04 \\
\hline 6 & 711.21 & 211.74 & 58.92 & 0.26 & 0.30 & 0.50 \\
\hline 7 & 710.18 & 211.39 & 58.76 & 0.14 & 0.16 & 0.28 \\
\hline
\end{tabular}




$$
K_{p c}=\frac{K_{p q}-\frac{1}{\cos \delta}}{\tan \phi}
$$

Thus, in the following sections, only $K_{p \gamma}$ and $K_{p q}$ coefficients will be presented; $K_{p c}$ may be computed using (12).

Table 4 presents the ratios $K_{\mathrm{p \gamma}}(3 \mathrm{D}) / K_{p \gamma}(2 \mathrm{D})$ for $\phi$ ranging from $20^{\circ}$ to $40^{\circ}$, for $\delta / \phi=1$, and for three values of $b / h(b / h$ $=0.25,1$, and 10).
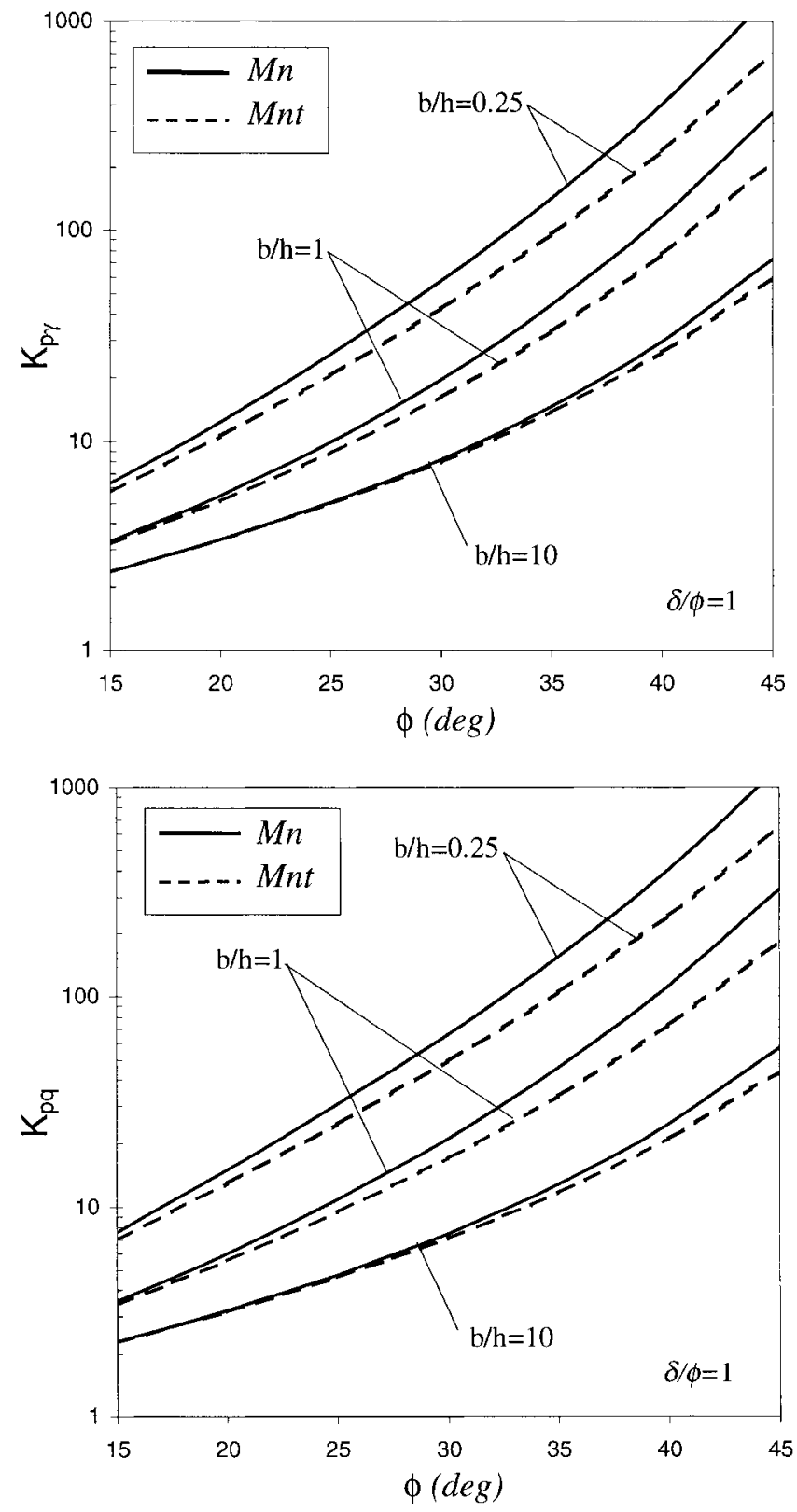

FIG. 8. Comparison of $K_{p \gamma}$ and $K_{p q}$ between $M n$ and Mnt Mechanisms $(\delta / \phi=1)$

TABLE 8. Ratio $K_{p \gamma}(3 D) / K_{p \gamma}(2 D)$ for $\delta / \phi=1$ from Mnt Mechanism

\begin{tabular}{c|c|c|c}
\hline \hline \multirow{2}{*}{$\begin{array}{c}\text { (deg) } \\
(1)\end{array}$} & $b / h=0.25$ & $b / h=1$ & $b / h=10$ \\
\cline { 2 - 4 } & $(2)$ & $(3)$ & $(4)$ \\
\hline 20 & 3.39 & 1.64 & 1.07 \\
30 & 6.16 & 2.36 & 1.15 \\
40 & 12.08 & 3.86 & 1.33 \\
\hline \hline
\end{tabular}

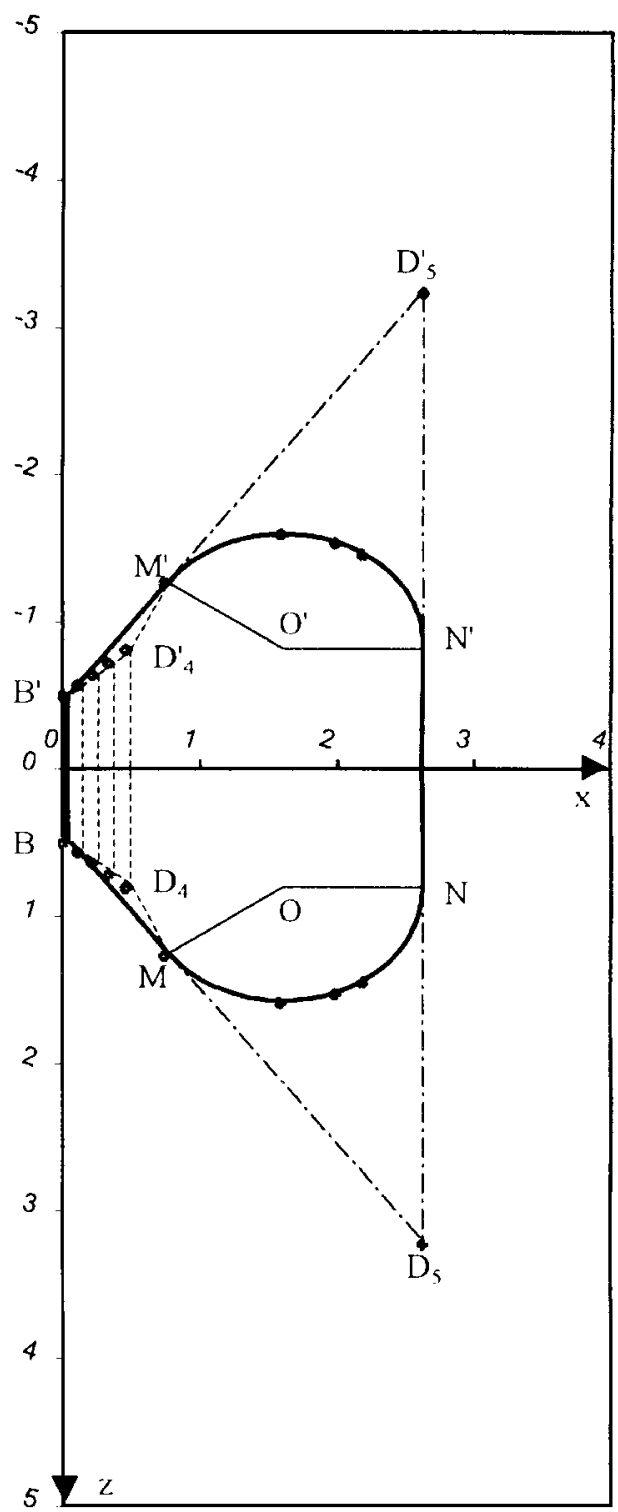

(a)

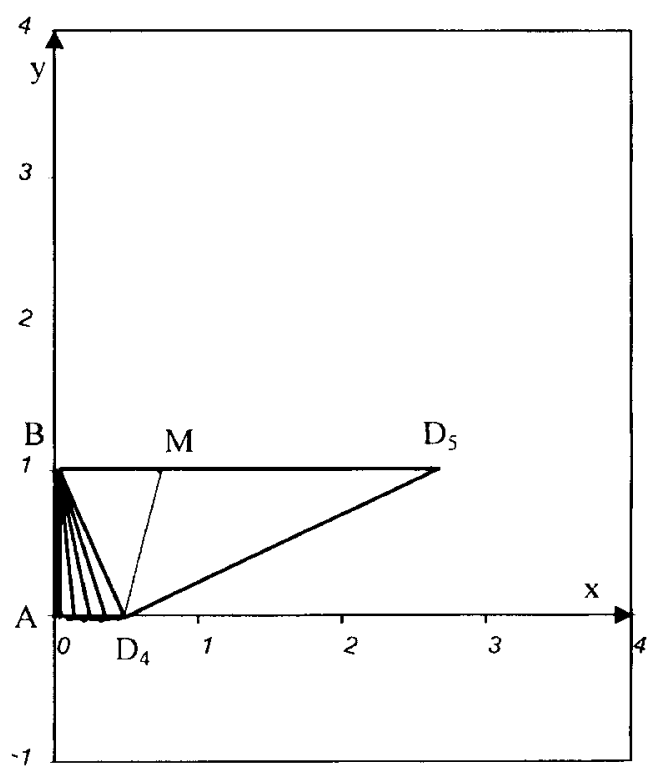

(b)

FIG. 9. Traces of Mnt Mechanism: (a) Plan View; (b) Vertical Section through $x O y\left(\phi=30^{\circ}, \delta / \phi=1\right.$, and $\left.b / h=1\right)$ 

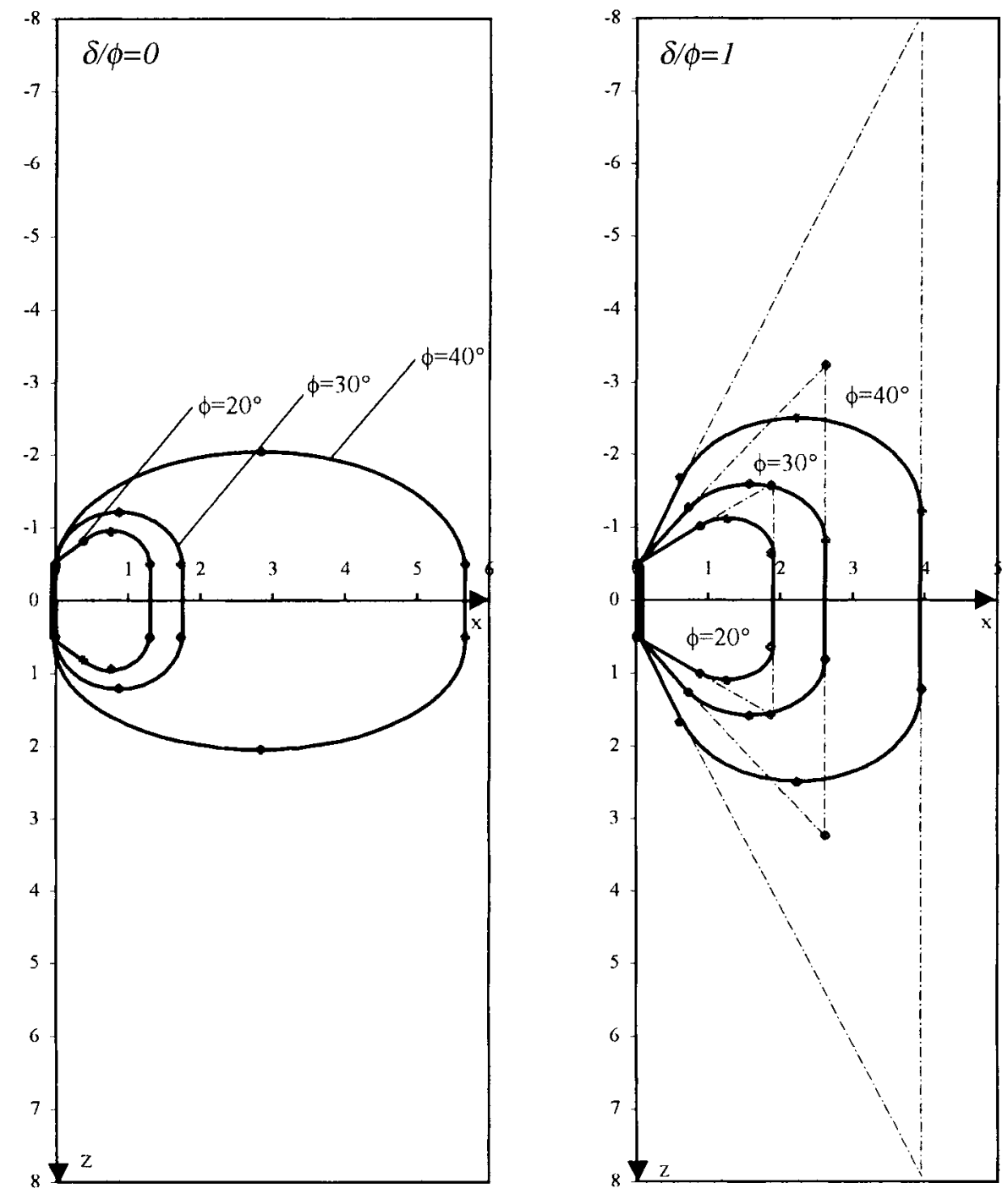

FIG. 10. Traces in Plan View of Mnt Mechanism for $\phi=20^{\circ}, 30^{\circ}, 40^{\circ} ; \delta / \phi=0$ and 1 ; and $b / h=1$

Notice that as the length $b / h$ increases, the ratio $K_{p \gamma}(3 \mathrm{D}) /$ $K_{p \gamma}(2 \mathrm{D})$ decreases; that is, the end effect decreases. It should be emphasized that, when $2 \mathrm{D}$ problems (i.e., large values of $b / h)$ are used, the passive earth pressure coefficients predicted based on the current analysis are identical to those of 2D analysis given by Chen (1975). As shown in Table 4, the end effects are most pronounced for great $\phi$ values. For instance, for $b / h=10$, the ratio $K_{p \gamma}(3 \mathrm{D}) / K_{p \gamma}(2 \mathrm{D})$ is equal to 1.09 when $\phi=20^{\circ}$ and attains 2.64 when $\phi=40^{\circ}$.

\section{Results from Mn Mechanism}

Table 5 presents the $K_{p \gamma}$ coefficient obtained from the $M n$ mechanism for various values of $n$ (the number of rigid blocks) when $\phi=45^{\circ} ; \delta / \phi=1$; and $b / h=0.25,1$, and 10 . This table shows that the upper-bound solution can be improved by increasing the number of rigid blocks. The reduction in the $K_{p \gamma}$ value decreases with the $n$ increase $(1.59 \%$ for $n=6$ and $b / h=1)$. Hence, all subsequent results are given for $n=5$ blocks.

Some results of $K_{p \gamma}$ and $K_{p q}$ obtained from the $M n$ mechanism are compared to those given by the $M 1$ mechanism in Fig. 6 for $\phi$ ranging from $15^{\circ}$ to $45^{\circ}$, for $\delta / \phi=1$, and for three values of $b / h(b / h=0.25,1$, and 10$)$.

As expected, the $M n$ mechanism gives better results than the $M 1$ mechanism. This may be explained by the fact that the geometry of the $M n$ mechanism is less restrictive than that of

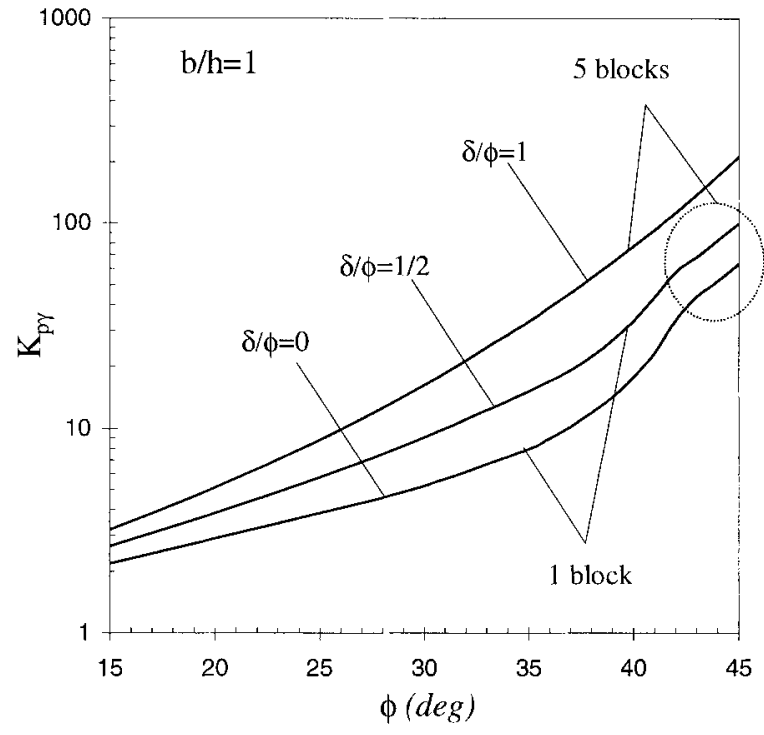

FIG. 11. $K_{p \gamma}$ versus $\phi$ for $\delta / \phi=0,1 / 2$, and 1 when $b / h=1$

the $M 1$ mechanism. For instance, when $\phi=40^{\circ}, \delta / \phi=1$, and $b / h=1$, the improvement of the solution attains $92.8 \%$.

Table 6 presents the ratios $K_{p \gamma}(3 \mathrm{D}) / K_{p \gamma}(2 \mathrm{D})$ for $\phi$ ranging from $20^{\circ}$ to $40^{\circ}$, for $\delta / \phi=1$, and for three values of $b / h(b / h$ $=0.25,1$, and 10). This table exhibits trends similar to those 
TABLE 9. $K_{p \gamma}$ Values for Various Governing Parameters $\phi, \delta$, and $b / h$

\begin{tabular}{|c|c|c|c|c|c|c|}
\hline \multirow[b]{2}{*}{$\begin{array}{l}b / h \\
(1)\end{array}$} & \multirow{2}{*}{$\begin{array}{c}\phi \\
\text { (deg) } \\
\text { (2) }\end{array}$} & \multicolumn{5}{|c|}{$\delta / \phi$} \\
\hline & & $\begin{array}{c}0 \\
(3)\end{array}$ & $\begin{array}{l}1 / 3 \\
(4)\end{array}$ & $\begin{array}{l}1 / 2 \\
\text { (5) }\end{array}$ & $\begin{array}{l}2 / 3 \\
(6)\end{array}$ & $\begin{array}{c}1 \\
(7)\end{array}$ \\
\hline \multirow[t]{7}{*}{0.25} & 15 & 3.633 & 3.634 & 3.635 & 3.636 & 3.637 \\
\hline & 20 & 5.399 & 5.400 & 5.401 & 5.402 & 5.403 \\
\hline & 25 & 7.983 & 7.984 & 7.985 & 7.986 & 7.987 \\
\hline & 30 & 11.886 & 11.887 & 11.888 & 11.889 & 11.890 \\
\hline & 35 & 20.044 & 20.045 & 20.046 & 20.047 & 20.048 \\
\hline & 40 & 50.430 & 50.431 & 50.432 & 50.433 & 50.434 \\
\hline & 45 & 215.455 & 215.456 & 215.457 & 215.458 & 215.459 \\
\hline \multirow[t]{7}{*}{0.5} & 15 & 2.673 & 3.062 & 3.282 & 3.524 & 4.054 \\
\hline & 20 & 3.726 & 4.538 & 5.041 & 5.629 & 6.994 \\
\hline & 25 & 5.229 & 6.849 & 7.963 & 9.379 & 12.776 \\
\hline & 30 & 7.443 & 10.604 & 13.096 & 16.634 & 25.085 \\
\hline & 35 & 11.984 & 17.354 & 22.855 & 32.487 & 54.064 \\
\hline & 40 & 28.594 & 40.954 & 53.74 & 79.700 & 131.753 \\
\hline & 45 & 114.009 & 148.475 & 178.689 & 224.310 & 379.494 \\
\hline \multirow[t]{7}{*}{1} & 15 & 2.190 & 2.490 & 2.658 & 2.841 & 3.191 \\
\hline & 20 & 2.887 & 3.487 & 3.853 & 4.279 & 5.139 \\
\hline & 25 & 3.850 & 5.001 & 5.779 & 6.760 & 8.798 \\
\hline & 30 & 5.221 & 7.391 & 9.067 & 11.418 & 16.273 \\
\hline & 35 & 7.954 & 11.518 & 15.150 & 21.308 & 33.202 \\
\hline & 40 & 17.676 & 25.317 & 31.218 & 49.269 & 77.015 \\
\hline & 45 & 63.152 & 82.517 & 99.555 & 125.324 & 212.364 \\
\hline \multirow[t]{7}{*}{2} & 15 & 1.946 & 2.189 & 2.340 & 2.492 & 2.737 \\
\hline & 20 & 2.466 & 2.956 & 3.252 & 3.593 & 4.171 \\
\hline & 25 & 3.159 & 4.069 & 4.677 & 5.435 & 6.746 \\
\hline & 30 & 4.111 & 5.777 & 7.038 & 8.787 & 11.764 \\
\hline & 35 & 5.939 & 8.600 & 11.279 & 15.683 & 22.607 \\
\hline & 40 & 12.218 & 17.499 & 22.962 & 32.329 & 49.371 \\
\hline & 45 & 37.520 & 49.289 & 59.708 & 75.515 & 128.306 \\
\hline \multirow[t]{7}{*}{5} & 15 & 1.798 & 2.022 & 2.145 & 2.256 & 2.451 \\
\hline & 20 & 2.211 & 2.633 & 2.885 & 3.133 & 3.561 \\
\hline & 25 & 2.743 & 3.505 & 4.006 & 4.542 & 5.456 \\
\hline & 30 & 3.444 & 4.801 & 5.808 & 6.965 & 8.948 \\
\hline & 35 & 4.73 & 6.849 & 8.938 & 11.519 & 16.035 \\
\hline & 40 & 8.942 & 12.808 & 16.806 & 21.145 & 32.361 \\
\hline & 45 & 21.743 & 28.869 & 35.262 & 45.043 & 76.983 \\
\hline \multirow[t]{7}{*}{10} & 15 & 1.748 & 1.962 & 2.069 & 2.169 & 2.352 \\
\hline & 20 & 2.125 & 2.524 & 2.748 & 2.954 & 3.348 \\
\hline & 25 & 2.604 & 3.315 & 3.770 & 4.178 & 5.004 \\
\hline & 30 & 3.222 & 4.473 & 5.394 & 6.209 & 7.958 \\
\hline & 35 & 4.327 & 6.266 & 8.150 & 9.870 & 13.730 \\
\hline & 40 & 7.851 & 11.244 & 14.754 & 17.226 & 26.424 \\
\hline & 45 & 16.153 & 21.665 & 26.684 & 34.430 & 59.215 \\
\hline \multirow[t]{7}{*}{ Strip } & 15 & 1.698 & 1.891 & 1.987 & 2.080 & 2.250 \\
\hline & 20 & 2.040 & 2.393 & 2.579 & 2.768 & 3.127 \\
\hline & 25 & 2.464 & 3.080 & 3.427 & 3.794 & 4.529 \\
\hline & 30 & 3.000 & 4.052 & 4.692 & 5.402 & 6.905 \\
\hline & 35 & 3.690 & 5.484 & 6.677 & 8.075 & 11.242 \\
\hline & 40 & 4.599 & 7.698 & 9.992 & 12.863 & 19.938 \\
\hline & 45 & 5.828 & 11.350 & 16.019 & 22.313 & 39.644 \\
\hline
\end{tabular}

observed in Table 4. On the other hand, for $b / h=10$ and $\phi=$ $40^{\circ}$, the present value of the ratio $K_{p \gamma}(3 \mathrm{D}) / K_{p \gamma}(2 \mathrm{D})=1.48$ may be compared with the previous value of $K_{p \gamma}(3 \mathrm{D}) / K_{p \gamma}(2 \mathrm{D})=2.64$ obtained from the $M 1$ mechanism. One may conclude that the present mechanism gives better predictions of the 3D effect.

Fig. 7 shows the plan view and the cross section through $x O y$ of the $M n$ mechanism as obtained from the minimization of $K_{p \gamma}$ when $\phi=30^{\circ}, \delta / \phi=1$, and $b / h=1$.

It can be observed that the volume of the last block $B D_{4} D_{5} B^{\prime} D_{4}^{\prime} D_{5}^{\prime}$ is significant in comparison to the remaining blocks.

\section{Results from Mnt Mechanism}

Table 7 presents the $K_{p \gamma}$ coefficient obtained from the Mnt mechanism for various values of $n$ when $\phi=45^{\circ} ; \delta / \phi=1$; and $b / h=0.25,1$, and 10 .

The reduction in the $K_{p \gamma}$ value is equal to $7.8 \%$ when $n=$ 3 and attains $0.3 \%$ when $n=6$ for $b / h=1$. One may conclude that the present mechanism rapidly converges to the optimal solution. Hence, in the following section, only five rigid blocks are used, which means that the minimization procedure is made with respect to nine angular parameters.

The results of $K_{p \gamma}$ and $K_{p q}$ obtained from the present mechanism are compared to those given by the $M n$ mechanism in Fig. 8.

As expected, the $M n t$ mechanism gives better results than the $M n$ mechanism. For instance, when $\phi=45^{\circ}, \delta / \phi=1$, and $b / h=1$, the improvement of the solution attains $42.6 \%$.

Table 8 presents the ratios $K_{p \gamma}(3 \mathrm{D}) / K_{p \gamma}(2 \mathrm{D})$ for $\phi$ ranging from $20^{\circ}$ to $40^{\circ}$, for $\delta / \phi=1$, and for three values of $b / h(b / h$ $=0.25,1$, and 10).

As shown in Table 8, the Mnt mechanism gives better predictions of the $3 \mathrm{D}$ effect because, for the same case considered in the preceding sections (i.e., $b / h=10$ and $\phi=40^{\circ}$ ), the present value of the ratio $K_{p \gamma}(3 \mathrm{D}) / K_{p \gamma}(2 \mathrm{D})=1.33$ is smaller than the one obtained from the $M n$ mechanism (cf. Table 6).

Fig. 9 shows the plan view and the cross section through

TABLE 10. $K_{p q}$ Values for Various Governing Parameters $\phi, \delta$, and $b / h$

\begin{tabular}{|c|c|c|c|c|c|c|}
\hline \multirow[b]{2}{*}{$\begin{array}{l}b / h \\
(1)\end{array}$} & \multirow{2}{*}{$\begin{array}{c}\phi \\
(\mathrm{deg}) \\
(2)\end{array}$} & \multicolumn{5}{|c|}{$\delta / \phi$} \\
\hline & & $\begin{array}{c}0 \\
(3)\end{array}$ & $\begin{array}{l}1 / 3 \\
(4)\end{array}$ & $\begin{array}{l}1 / 2 \\
(5)\end{array}$ & $\begin{array}{l}2 / 3 \\
(6)\end{array}$ & $\begin{array}{c}1 \\
(7)\end{array}$ \\
\hline \multirow{7}{*}{0.25} & 15 & 4.588 & 5.315 & 5.735 & 6.201 & 6.983 \\
\hline & 20 & 7.068 & 8.704 & 9.736 & 10.960 & 13.015 \\
\hline & 25 & 10.736 & 14.202 & 16.635 & 19.770 & 24.817 \\
\hline & 30 & 16.329 & 23.415 & 29.140 & 37.382 & 49.352 \\
\hline & 35 & 28.104 & 40.698 & 53.606 & 77.039 & 104.684 \\
\hline & 40 & 72.265 & 103.502 & 135.815 & 170.861 & 243.616 \\
\hline & 45 & 221.247 & 283.828 & 336.637 & 412.522 & 646.788 \\
\hline \multirow[t]{7}{*}{0.5} & 15 & 3.153 & 3.628 & 3.900 & 4.198 & 4.625 \\
\hline & 20 & 4.563 & 5.583 & 6.219 & 6.967 & 8.057 \\
\hline & 25 & 6.606 & 8.690 & 10.135 & 11.984 & 14.599 \\
\hline & 30 & 9.664 & 13.810 & 17.113 & 21.829 & 27.909 \\
\hline & 35 & 16.014 & 23.190 & 30.545 & 43.615 & 57.371 \\
\hline & 40 & 39.512 & 56.591 & 74.259 & 91.492 & 130.190 \\
\hline & 45 & 115.741 & 148.661 & 176.444 & 216.319 & 338.705 \\
\hline \multirow[t]{7}{*}{1} & 15 & 2.432 & 2.777 & 2.972 & 3.182 & 3.419 \\
\hline & 20 & 3.307 & 4.014 & 4.449 & 4.956 & 5.543 \\
\hline & 25 & 4.540 & 5.926 & 6.873 & 8.073 & 9.445 \\
\hline & 30 & 6.332 & 8.999 & 11.084 & 13.951 & 17.124 \\
\hline & 35 & 9.969 & 14.436 & 19.006 & 25.670 & 33.627 \\
\hline & 40 & 23.136 & 33.136 & 43.481 & 51.724 & 73.351 \\
\hline & 45 & 62.912 & 80.988 & 96.248 & 118.102 & 184.474 \\
\hline \multirow[t]{7}{*}{2} & 15 & 2.068 & 2.345 & 2.499 & 2.620 & 2.798 \\
\hline & 20 & 2.677 & 3.223 & 3.554 & 3.848 & 4.256 \\
\hline & 25 & 3.505 & 4.536 & 5.229 & 5.902 & 6.819 \\
\hline & 30 & 4.666 & 6.585 & 8.055 & 9.562 & 11.656 \\
\hline & 35 & 6.946 & 10.059 & 13.218 & 16.622 & 21.638 \\
\hline & 40 & 14.947 & 21.408 & 26.666 & 31.723 & 44.748 \\
\hline & 45 & 36.374 & 47.008 & 55.993 & 68.811 & 107.059 \\
\hline \multirow[t]{7}{*}{5} & 15 & 1.848 & 2.081 & 2.185 & 2.271 & 2.409 \\
\hline & 20 & 2.296 & 2.741 & 2.969 & 3.148 & 3.453 \\
\hline & 25 & 2.882 & 3.694 & 4.176 & 4.533 & 5.189 \\
\hline & 30 & 3.666 & 5.127 & 6.147 & 6.865 & 8.277 \\
\hline & 35 & 5.133 & 7.433 & 9.615 & 11.077 & 14.269 \\
\hline & 40 & 10.034 & 13.923 & 16.376 & 19.515 & 27.268 \\
\hline & 45 & 20.194 & 26.327 & 31.524 & 38.875 & 60.019 \\
\hline \multirow[t]{7}{*}{10} & 15 & 1.773 & 1.986 & 2.072 & 2.152 & 2.274 \\
\hline & 20 & 2.168 & 2.577 & 2.746 & 2.906 & 3.173 \\
\hline & 25 & 2.673 & 3.410 & 3.748 & 4.060 & 4.620 \\
\hline & 30 & 3.333 & 4.637 & 5.316 & 5.924 & 7.100 \\
\hline & 35 & 4.528 & 6.558 & 7.951 & 9.155 & 11.708 \\
\hline & 40 & 8.263 & 10.838 & 12.821 & 15.303 & 21.219 \\
\hline & 45 & 14.571 & 19.177 & 23.101 & 28.599 & 43.854 \\
\hline \multirow[t]{7}{*}{ Strip } & 15 & 1.698 & 1.878 & 1.956 & 2.027 & 2.133 \\
\hline & 20 & 2.040 & 2.365 & 2.516 & 2.655 & 2.881 \\
\hline & 25 & 2.464 & 3.026 & 3.302 & 3.565 & 4.021 \\
\hline & 30 & 3.000 & 3.947 & 4.443 & 4.937 & 5.846 \\
\hline & 35 & 3.690 & 5.278 & 6.173 & 7.105 & 8.949 \\
\hline & 40 & 4.599 & 7.286 & 8.928 & 10.750 & 14.643 \\
\hline & 45 & 5.828 & 10.486 & 13.657 & 17.367 & 26.168 \\
\hline
\end{tabular}


$x O y$ of the Mnt mechanism as obtained from the minimization of $K_{p \gamma}$ when $\phi=30^{\circ}, \delta / \phi=1$, and $b / h=1$.

In the plan view, the Mnt mechanism is bounded by the traces of the lateral planes $B M$ and $B^{\prime} M^{\prime}$, the trace of the lower plane $N N^{\prime}$, and the traces of the conical sectors $M N$ and $M^{\prime} N^{\prime}$. As is the case with $M n$, the present failure mechanism mobilizes a great volume for the last block.

Fig. 10 shows the traces in the plan view of the Mnt mechanism for $\phi=20^{\circ}, 30^{\circ}$, and $40^{\circ}$ when $\delta / \phi=0$ and 1 and $b / h$ $=1$.

For $\delta / \phi=0$, one can observe a significant change in the failure surface between $\phi=30^{\circ}$ and $40^{\circ}$. This can be explained by the fact that, for a smooth wall and when $\phi<30^{\circ}$, the critical failure mechanism as given by the numerical minimization is obtained for $n=1$ (i.e., one-block truncated mechanism). The five-block mechanism is of interest only for great $\phi$ and $\delta$ values.

Finally, it should be mentioned that the trace of the present failure mechanism in plan view is smooth as observed experimentally by Meksaouine (1993).

\section{Discussion of Results}

As shown before, the Mnt mechanism gives the least upperbound solution to the $3 \mathrm{D}$ passive earth pressure problem.

Fig. 11 shows the variation of $K_{p \gamma}$ with $\phi$ for $\delta / \phi=0,1 / 2$, and 1 when $b / h=1$.

For a rough wall $(\delta / \phi>2 / 3)$, the critical $K_{p \gamma}$ values are obtained with the maximal allowable number of blocks (i.e., five blocks in the present case). However, when $\delta / \phi<2 / 3$ and $\phi<40^{\circ}$, the critical failure mechanism as obtained from the numerical minimization is reduced to the one-block truncated mechanism. On the other hand, it should be mentioned that for $b / h>7$ the maximal number of blocks is needed to obtain the optimal solution. This is to be expected because, in that case (i.e., 2D analysis), the one-block mechanism greatly overestimates the passive earth pressure coefficients for great $\phi$ and $\delta$ values.

Finally, extensive numerical results of $K_{p \gamma}$ and $K_{p q}$ as obtained from the $M n t$ mechanism for various governing parameters are given in Tables 9 and 10 for practical use in geotechnical engineering.

\section{Comparison with Existing Solutions}

Although the 2D passive earth pressure problem has been widely treated in the literature using different approaches, the 3D passive earth pressure problem has received little attention apart from the work of Blum (1932) using the limit-equilibrium method. As shown in Fig. 12, Blum's mechanism is an extension into three dimensions of the traditional one-block Coulomb mechanism in which the frictional forces at the lat-

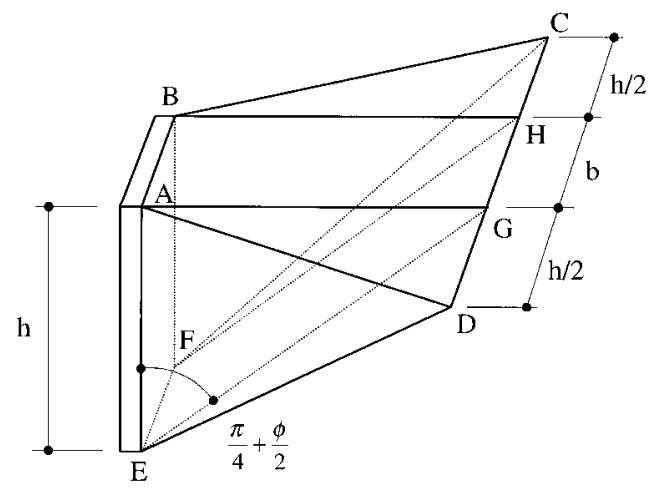

FIG. 12. Blum's Failure Mechanism eral planes are neglected. According to Blum (1932), the 3D passive earth force is given by

$$
P_{p}=\frac{1}{2} \gamma h^{2} b \tan ^{2}\left(\frac{\pi}{4}+\frac{\phi}{2}\right)+\gamma \frac{h^{3}}{6} \tan ^{2}\left(\frac{\pi}{4}+\frac{\phi}{2}\right)
$$

Figs. 13( $\mathrm{a}$ and $\mathrm{b}$ ) show the comparison between the present results and those given by Blum (1932) for $\phi=15^{\circ}$ and $35^{\circ}$; for $\delta / \phi=0,1 / 3,1 / 2,2 / 3$, and 1 ; and for different values of $b / h$.

These figures clearly show that Blum's solutions are in good agreement with the present solutions only for loose sand and a smooth wall. However, for dense sand and rough wall, Blum's solutions greatly underestimate the passive earth pressure coefficients. This difference may be explained by the fact that the lower slip surface in Blum's mechanism is assumed to be planar. Furthermore, Blum made an a priori assumption
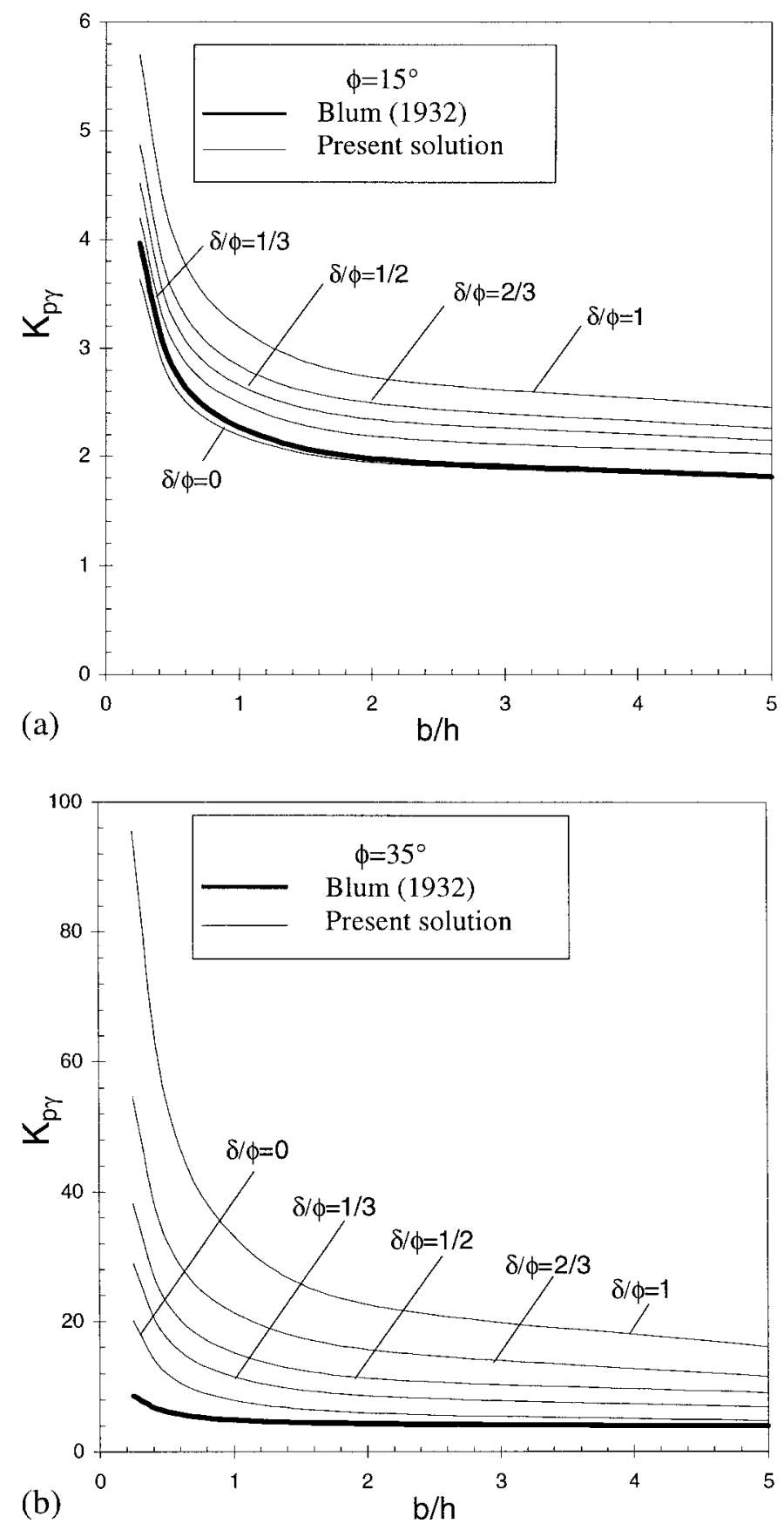

FIG. 13. Comparison with Blum (1932) for: (a) $\phi=15^{\circ}$; (b) $\phi=$ $35^{\circ}$ 
concerning the length of $D C$ at the ground level (cf. Fig. 12). Finally, Blum neglected the frictional forces on the lateral planes $A E D$ and $B F C$.

\section{CONCLUSIONS}

Similar to the 2D analysis, the one-block 3D failure mechanism $M 1$ greatly overestimates the passive earth pressures for great $\phi$ and $\delta$ values.

The multiblock mechanism $M n$ improves the results given by the $M 1$ mechanism due to the flexibility of this mechanism especially for great values of $\phi$ and $\delta$. It gives better predictions of the 3D effect. However, the trace of the failure mechanism in the plan view is not as smooth as observed experimentally by Meksaouine (1993).

Finally, the truncated multiblock mechanism is more efficient than the $M n$ mechanism because it gives smaller upperbound solutions and leads to a critical slip surface in the plan view that is similar to that observed experimentally.

The numerical results have shown that the truncated multiblock mechanism is reduced to the truncated one-block mechanism for $\delta / \phi<2 / 3$ and $\phi<40^{\circ}$; otherwise, the truncated five-block mechanism is needed to obtain the optimal upperbound solutions.

The comparison of the results obtained from the Mnt mechanism with those given by the classical Blum solutions has shown that this author greatly underestimates the passive earth pressure coefficients for a rough wall and a dense sand.

Finally, numerical results based on the Mnt mechanism for various governing parameters are given for practical use.

\section{APPENDIX. REFERENCES}

Blum, H. (1932). "Wirtschaftliche Dalbenformen und deren Berechnung." Bautechnik, 10(5), 122-135 (in German).

Caquot, A., and Kérisel, J. (1949). Traité de mécanique des sols, Gauthier-Villars, Paris (in French).

Chen, W. F. (1975). Limit analysis and soil plasticity, Elsevier Science, Amsterdam.

Chen, W. F., and Rosenfarb, J. L. (1973). "Limit analysis solutions of earth pressure problems." Soils and Found., Tokyo, 13(4), 45-60.

Collins, I. F. (1969). "The upper-bound theorem for rigid/plastic solids to include Coulomb friction." J. Mech. Phys. Solids, 17, 323-338.

Collins, I. F. (1973). "A note on the interpretation of Coulomb's analysis of the thrust on a rough retaining wall in terms of the limit theorems of plasticity theory." Géotechnique, London, 24(1), 106-108.
Coulomb, C. A. (1773). "Sur une application des règles de maximis et minimis à quelques problèmes de statique relatifs à l'architecture." Acad. R. Sci. Mém. Math. Phys., 7, 343-382 (in French).

Drescher, A., and Detournay, E. (1993). "Limit load in translational failure mechanisms for associative and non-associative materials." Géotechnique, London, 43(3), 443-456.

Lee, I. K., and Herington, J. R. (1972). "A theoretical study of the pressures acting on a rigid wall by a sloping earth on rockfill." Géotechnique, London, 22(1), 1-26.

Lysmer, J. (1970). "Limit analysis of plane problems in soil mechanics." J. Soil Mech. and Found. Div., ASCE, 96(4), 1311-1334.

Meksaouine, M. (1993). "Etude expérimentale et théorique de la poussée passive sur pieux rigides." PhD thesis, Institut National des Sciences Appliquées de Lyon, Lyon, France (in French).

Michalowski, R. L. (1999). "Closure on 'Stability of uniformly reinforced slopes.'” J. Geotech. and Geoenvir. Engrg., ASCE, 125(1), 81-86.

Michalowski, R. L., and Shi, L. (1995). "Bearing capacity of footings over two-layer foundation soils." J. Geotech. Engrg., ASCE, 121(5), 421-428.

Michalowski, R. L., and Shi, L. (1996). "Closure on 'Bearing capacity of footings over two-layer foundation soils." "J. Geotech. Engrg., ASCE, 122(8), 701-703.

Mroz, Z., and Drescher, A. (1969). "Limit plasticity approach to some cases of flow of bulk solids." J. Engrg. Ind. Trans. Am. Soc. Mech. Engrs., 91, 357-364.

Rahardjo, H., and Fredlund, D. G. (1984). "General limit equilibrium method for lateral earth force." Can. Geotech. J., Ottawa, 21(1), $166-175$.

Regenass, P. (1999). “Application de la méthode cinématique de l'analyse limite au calcul de la butée tridimensionnelle et de la charge limite de plaques d'ancrage superficielles." PhD thesis, Université Louis Pasteur, Strasbourg, France (in French).

Shields, D. H., and Tolunay, A. Z. (1972). "Passive pressure coefficients for sand by the Terzaghi and Peck method." Can. Geotech. J., Ottawa, 9(4), 501-503.

Shields, D. H., and Tolunay, A. Z. (1973). "Passive pressure coefficients by methods of slices." J. Soil Mech. and Found. Div., ASCE, 99(12), 1043-1053.

Sokolovski, V. V. (1960). Static of granular media, Butterworth's, London.

Soubra, A.-H. (2000). "Static and seismic passive earth pressure coefficients on rigid retaining structures." Can. Geotech. J., Ottawa, 37(2), in press.

Soubra, A.-H., Kastner, R., and Benmansour, A. (1999). "Passive earth pressures in the presence of hydraulic gradients." Géotechnique, London, 49(3), 319-330.

Terzaghi, K. (1943). Theoretical soil mechanics, Wiley, New York.

Zakerzadeh, N., Fredlund, D. G., and Pufahl, D. E. (1999). "Interslice force functions for computing active and passive earth force." Can. Geotech. J., Ottawa, 36(6), 1015-1029. 